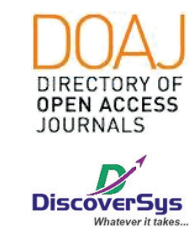

Published by DiscoverSys

\section{Hubungan posisi dan lama duduk dengan nyeri punggung bawah pada pemain game online}

\author{
Putu Gede Pradipta Mahardika Wijaya, ${ }^{1 *}$ Ida Ayu Sri Wijayanthi, ${ }^{2}$ \\ Ketut Widyastuti²
}

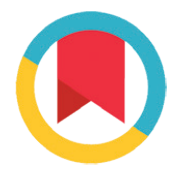

CrossMark

\title{
ABSTRACT
}

Introduction: The public's interest in online games is seen by the growing number of internet cafes and online games that are increasingly in Indonesia. Online games are starting to be considered something addictive. Position and duration of playing online game players that are usually more than 4 hours causes online game players often experience lower back pain. This study aims to determine the position and duration of sitting with low back pain in online game players.

Methods: This study is a cross-sectional analytic study with a qualitative study design. The research data uses primary data taken directly by filling out the questionnaire in Game Online in the West Denpasar sub-district for the period November 2018 to December 2018. The sample collection technique uses the total sampling method. Result: The total sample in this study was 80 respondents, based on age distribution ranging from 17 to 30 years with an average age of
20.86 years. The highest proportion of body mass index in the risk group ( $>23.0$ ) was 55 people (68.75\%). The proportion of ergonomic sitting positions is 20 people $(25 \%)$ while the proportion of nonergonomic sitting positions is 60 people (75\%). The proportion of respondents who sat $\leq 4$ hours was 23 people $(28.75 \%)$ while the proportion of respondents sitting $>4$ hours was 57 people (71.25\%). The proportion of respondents who complained of low back pain was 60 people (75\%) and those who did not complain of 20 lower back pain (25\%). The highest proportion who experience low back pain in respondents with non-ergonomic sitting position is $75 \%$. The highest proportion who experienced low back pain in respondents with a sitting time $>4$ hour was $71.25 \%$.

Conclusion: Non-ergonomic sitting position and duration sitting that more than 4 hours are risk factors that affect lower back pain in online game players.

Keywords: lower back pain, sitting position, sitting duration, online game player

Cite This Article: Wijaya, P.G.P.M., Wijayanthi, I.A.S., Widyastuti, K. 2019. Hubungan posisi dan lama duduk dengan nyeri punggung bawah pada pemain game online. Intisari Sains Medis 10(3): 834-839. D0I: 10.15562/ism.v10i3.495

\section{ABSTRAK}

Latar Belakang: Ketertarikan masyarakat terhadap game online tampak dengan berkembangnya usaha warung internet dan gameonline yang semakin banyak di Indonesia. Aktivitas duduk dengan posisi dan durasi waktu bermain pemain game online yang biasanya lebih dari 4 jam menyebabkan para pemain game online sering mengalami nyeri punggung bawah. Penelitian ini bertujuan untuk mengetahui hubungan posisi dan lama duduk dengan nyeri punggung bawah pada pemain game online.

Metode: Penelitian ini merupakan penelitian analitik cross-sectional dengan desain studi kualitatif. Data penelitian menggunakan data primer yang diambil langsung dengan pengisian kuisioner di Game Online wilayah kecamatan Denpasar Barat periode November 2018 hingga Desember 2018. Teknik pengumpulan sampel menggunakan metode total sampling.

Hasil: Total sampel pada penelitian ini adalah 80 responden, berdasarkan distribusi usia berkisar 17 hingga 30 tahun dengan rerata usia 20,86 tahun. Proporsi indeks massa tubuh terbanyak pada kelompok berisiko (>23,0) sebanyak 55 orang (68,75\%). Proporsi posisi duduk ergonomis sebanyak 20 orang (25\%) sedangkan proporsi posisi duduk tidak ergonomis sebesar 60 orang (75\%). Proporsi responden yang duduk $\leq 4$ jam sebesar 23 orang $(28,75 \%)$ sedangkan proporsi responden yang duduk $>4$ jam sebesar 57 orang (71,25\%). Proporsi responden yang mengeluh nyeri punggung bawah ada 60 orang (75\%) dan yang tidak mengeluh adanya nyeri punggung bawah sebanyak 20 orang (25\%). Proporsi paling banyak yang mengalami nyeri punggung bawah pada responden dengan posisi duduk tidak ergonomis sebesar 75\%. Proporsi paling banyak yang mengalami nyeri punggung bawah pada responden dengan lama duduk $>4$ jam sebesar $71,25 \%$.

Simpulan: Posisi duduk tidak ergonomis dan lama duduk lebih dari 4 jam merupakan faktor risiko yang mempengaruhi nyeri punggung bawah pada pemain game online.
Universitas Udayana

pradiptamahardika@gmail.com

Diterima: 08-04-2019

Disetujui: 24-11-2019

Diterbitkan: 01-12-2019
Kata kunci: nyeri punggung bawah, posisi duduk,lama duduk, pemain game online

Cite Pasal Ini: Wijaya, P.G.P.M., Wijayanthi, I.A.S., Widyastuti, K. 2019. Hubungan posisi dan lama duduk dengan nyeri punggung bawah pada pemain game online. Intisari Sains Medis 10(3): 834-839. D0I: 10.15562/ism.v10i3.495 


\section{PENDAHULUAN}

Pentingnya penggunaan internet di Indonesia makin disadari oleh masyarakatnya dari berbagai kalangan. ${ }^{1}$ Selain menggunakan internet untuk menyelesaikan tugas sekolah atau pekerjaan, kenyataannya banyak yang beralih pada game online. Dewasa ini ketertarikan masyarakat terhadap game-online tampak dengan berkembangnya usaha warung internet dan game-online yang semakin banyak di Indonesia. ${ }^{2}$ Apabila tidak bisa mengontrol diri, Game Online bisa menimbulkan dampak yang buruk bagi perkembangan remaja. ${ }^{3}$ Game pun mulai dianggap sebagai sesuatu yang addict. Para gamers mampu duduk berlama-lama demi game dan bertahan disana tanpa menginginkan suatu gangguan yang mampu memecah konsentrasinya dalam bermain Game Online tersebut. ${ }^{4}$

Aktivitas duduk dengan posisi dan durasi waktu bermain pemain game online yang biasanya lebih dari 4 jam menyebabkan para pemain game online sering mengalami nyeri pada bagian pantat atau nyeri punggung bagian bawah, apabila terlalu lama duduk yang disertai nyeri dan kesemutan pada bagian pantat sampai paha bawah. Pemain game online juga sering mengalami nyeri pada saat bangun dari tempat duduk serta pada saat berganti posisi duduk. ${ }^{5}$

Nyeri punggung bawah merupakan salah satu gangguan muskuloskeletal yang disebabkan oleh aktivitas tubuh yang kurang baik. Nyeri punggung bawah diklasifikasikan kedalam 2 kelompok yaitu kronik dan akut. Nyeri punggung bawah akut terjadi dalam waktu kurang dari 12 minggu, sedangkan Nyeri punggung bawah kronik terjadi dalam waktu 3 bulan. ${ }^{6}$ Gejala yang sering terjadi adalah adanya nyeri pada bagian pantat, spasme otot dan adanya parasthesia oleh karena kurangnya sirkulasi darah yang mengalir di tubuh. ${ }^{5}$ Saat beraktifitas dalam waktu yang lama dengan posisi yang menetap akan menyebabkan otot bekerja terus-menerus dan pada keadaan yang statis sehingga akan terjadi adaptasi pada jaringan tersebut yang berakibat otot mengalami ketegangan atau pemendekan dan akan menekan saraf yang ada di sekitarnya yang nantinya akan menimbulkan nyeri pada daerah tersebut dan menjalar ke arah inervesi dari saraf tersebut. Durasi lama duduk ialah posisi duduk lebih dari 4 jam per hari. Sikap duduk yang tegang dan kaku akibat kursi yang tidak sesuai dengan antropometri pemakai dapat menambah tekanan yang terjadi dan merupakan penyebab utama adanya keluhan-keluhan pada otot skeletal. ${ }^{5}$

\section{METODE}

Penelitian ini adalah penelitian analitik kualitatif dengan desain studi cross sectional. Penelitian ini dilaksanakan di Acyuta Game Online, Ultima G-1 Gaming Center, Twins Game Online, Playhouse Online Game, JJ Game Online, ATC Game Onlne, Komodo Game Center Denpasar, Bali. pada bulan November - Desember 2018.

Subyek penelitian adalah Pemain game online pada Game Online yang memenuhi kriteria inklusi yaitu Berusia $\geq 13$ tahun, Waktu bermain $\geq 1$ jam. Kriteria eksklusi sampel adalah Pemain game online pada Game Online yang memiliki riwayat trauma pada tulang belakang. Teknik pengambilan sampel dalam penelitian ini menggunakan metode total sampling

Data berupa data primer yang dikumpulkan dengan memberikan kuesioner kepada sample penelitian. Kuesioner terbagi dalam 3 bagian yaitu bagian (I) Identitas Responden, (II) Pertanyaan mengenai Keluhan Nyeri Punggung Bawah dan bagian (III) Metode TULA untuk menilai Posisi duduk. Kuesioner bagian (I) dan (II) diisi sendiri oleh responden sedangkan kuesioner bagian (III) diisi oleh peneliti dengan menanyakan dan pengamatan langsung pada responden.

Data kemudian dianalisis dengan bantuan piranti lunak SPSS. Uji chi-square digunakan untuk mengetahui variabel posisi duduk dan variabel nyeri punggung dengan tingkat signifikan $\alpha=0,05$ (5\%). Hasil uji ini dinyatakan dengan p value, nilai $\mathrm{p}$ value $<0,05$ dikatakan terdapat hubungan posisi dan lama duduk dengan nyeri punggung bawah pada pemain game online.

\section{HASIL}

Tabel 1 menunjukkan bahwa dari 80 responden, proporsi usia terbanyak terdapat pada rentang usia $<25$ tahun sebanyak 72 orang (90\%).Proporsi indeks massa tubuh terbanyak pada kelompok berisiko $(>23,0)$ sebanyak 55 orang $(68,75 \%)$. Proporsi posisi duduk ergonomis sebanyak 20 orang (25\%) sedangkan proporsi posisi duduk tidak ergonomis sebesar 60 orang (75\%). Proporsi responden yang duduk $\leq 4$ jam sebesar 23 orang $(28,75 \%)$ sedangkan proporsi responden yang duduk $>4$ jam sebesar 57 orang (71,25\%). Proporsi responden yang mengeluh nyeri punggung bawah ada 60 orang (75\%) dan yang tidak mengeluh adanya nyeri punggung bawah sebanyak 20 orang (25\%).

Berdasarkan Tabel 2, dapat dijelaskan bahwa dari 80 responden, berdasarkan distribusi usia berkisar 17 hingga 30 tahun dengan rerata usia 20,86 tahun. Distribusi usia dapat digolongkan menjadi usia $<25$ tahun dengan persentasenya sebesar $90 \%$ (72 orang). Persentase responden yang berusia $<25$ tahun yang mengalami nyeri punggung bawah sebesar $65 \%$ (52 orang) dan persentase yang tidak mengalami nyeri punggung bawah sebesar 
Tabel 1 Karakteristik Responden

\begin{tabular}{lcl}
\hline Karakteristik & N & \% \\
\hline Usia & 72 & 90 \\
$\quad<25$ tahun & 8 & 10 \\
$\quad \geq 25$ tahun & & \\
Indeks Massa Tubuh & 55 & 68,75 \\
$\quad$ Berisiko $(>23,0)$ & 25 & 31,25 \\
$\quad$ Tidak Berisiko $(\leq 23,0)$ & & \\
Posisi Duduk & 20 & 25 \\
$\quad$ Ergonomis & 60 & 75 \\
Tidak Ergonomis & & \\
Lama Duduk & 23 & 28,75 \\
$\leq 4$ jam & 57 & 71,25 \\
$>4$ jam & & \\
Nyeri Punggung Bawah & 60 & 25 \\
Iya & 20 & 75 \\
Tidak & & \\
\hline
\end{tabular}

Tabel 2 Hubungan antara Faktor Risiko Usia Terhadap Keluhan Nyeri Punggung Bawah

\begin{tabular}{|c|c|c|c|c|c|c|c|}
\hline \multirow[b]{3}{*}{ Usia } & \multicolumn{4}{|c|}{$\begin{array}{c}\text { Keluhan Nyeri } \\
\text { Punggung Bawah }\end{array}$} & & & \multirow[b]{3}{*}{ Nilai p } \\
\hline & \multicolumn{2}{|c|}{ Ada } & \multicolumn{2}{|c|}{ Tidak } & \multicolumn{2}{|c|}{ Total } & \\
\hline & $\mathbf{N}$ & $\%$ & $\mathbf{N}$ & $\%$ & $\mathbf{N}$ & $\%$ & \\
\hline$<25$ tahun & 52 & 65 & 20 & 25 & 72 & 90 & 0101 t \\
\hline$\geq 25$ tahun & 8 & 10 & 0 & 0 & 8 & 10 & 0.191 \\
\hline Total & 60 & 75 & 20 & 25 & 80 & 100 & \\
\hline
\end{tabular}

* uji chi-square

Tabel 3 Hubungan antara Faktor Risiko Indeks Massa Tubuh Terhadap Keluhan Nyeri Punggung Bawah

\begin{tabular}{|c|c|c|c|c|c|c|c|}
\hline \multirow{3}{*}{$\begin{array}{l}\text { Indeks Massa } \\
\text { Tubuh }\end{array}$} & \multicolumn{4}{|c|}{$\begin{array}{c}\text { Keluhan Nyeri } \\
\text { Punggung Bawah }\end{array}$} & & & \multirow[b]{3}{*}{ Nilai $p$} \\
\hline & \multicolumn{2}{|c|}{ Ada } & \multicolumn{2}{|c|}{ Tidak } & \multicolumn{2}{|c|}{ Total } & \\
\hline & $\mathbf{N}$ & $\%$ & $\mathbf{N}$ & $\%$ & $\mathbf{N}$ & $\%$ & \\
\hline$\leq 23,0$ & 17 & 21,25 & 8 & 10 & 25 & 31,25 & \multirow{2}{*}{0.152} \\
\hline$>23,0$ & 43 & 53,75 & 12 & 15 & 55 & 68,75 & \\
\hline Total & 60 & 75 & 20 & 25 & 80 & 100 & \\
\hline
\end{tabular}

*uji chi-square

Tabel 4 Hubungan antara Posisi Duduk Terhadap Keluhan Nyeri Punggung Bawah

\begin{tabular}{|c|c|c|c|c|c|c|c|}
\hline \multirow[b]{3}{*}{ Posisi Duduk } & \multicolumn{4}{|c|}{$\begin{array}{c}\text { Keluhan Nyeri } \\
\text { Punggung Bawah }\end{array}$} & & & \multirow[b]{3}{*}{ Nilai $p$} \\
\hline & \multicolumn{2}{|c|}{ Ada } & \multicolumn{2}{|c|}{ Tidak } & \multicolumn{2}{|c|}{ Total } & \\
\hline & $\mathbf{N}$ & $\%$ & $\mathbf{N}$ & $\%$ & $\mathbf{N}$ & $\%$ & \\
\hline Ergonomis (Skor Rula 1-2) & 0 & 0 & 20 & 25 & 20 & 25 & \multirow{2}{*}{0,000} \\
\hline Tidak Ergonomis (Skor Rula 3-7) & 60 & 75 & 0 & 0 & 60 & 75 & \\
\hline Total & 60 & 75 & 20 & 25 & 80 & 100 & \\
\hline
\end{tabular}

*uji chi-square 
Tabel 5 Hubungan antara Lama Duduk Terhadap Keluhan Nyeri Punggung Bawah

\begin{tabular}{|c|c|c|c|c|c|c|c|}
\hline \multirow[b]{3}{*}{ Lama Duduk } & \multicolumn{4}{|c|}{$\begin{array}{c}\text { Keluhan Nyeri } \\
\text { Punggung Bawah }\end{array}$} & & & \multirow[b]{3}{*}{ Nilai p } \\
\hline & \multicolumn{2}{|c|}{ Ada } & \multicolumn{2}{|c|}{ Tidak } & \multicolumn{2}{|c|}{ Total } & \\
\hline & $\mathbf{N}$ & $\%$ & $\mathbf{N}$ & $\%$ & $\mathbf{N}$ & $\%$ & \\
\hline$>4$ jam & 57 & 71,25 & 0 & 0 & 57 & 71,25 & \multirow{2}{*}{0,000} \\
\hline$\leq 4 \mathrm{jam}$ & 0 & 0 & 23 & 28,75 & 23 & 28,75 & \\
\hline Total & 57 & 71,25 & 23 & 28,75 & 80 & 100 & \\
\hline
\end{tabular}

${ }^{*}$ uji chi-square

$25 \%$ (20 orang). Pada usia $\geq 25$ tahun sebesar $10 \%$ (8 orang). Persentase responden yang berusia $\geq 25$ tahun yang mengalami nyeri punggung bawah sebesar $10 \%$ (8 orang) dan persentase responden yang tidak mengalami nyeri punggung bawah sebesar $0 \%$ (0 orang). Hal tersebut menunjukkan bahwa pemain game online lebih banyak direntang usia $<25$ tahun. Setelah data dianalisis dengan uji chi square, didapatkan nilai expected count $<5$, maka uji yang digunakan adalah uji Fisher's Exact. Hasil uji Fisher menemukan nilai $\mathrm{p}=0.191$. Nilai ini menunjukkan tidak adanya hubungan bermakna antara keluhan nyeri punggung bawah dengan faktor risiko usia.

Berdasarkan index massa tubuh dibagi menjadi 2 golongan, yaitu indeks massa tubuh yang berisiko (>23,0) sebesar 68,75\% (55 orang). Persentase responden dengan indeks massa tubuh berisiko yang mengalami nyeri punggung bawah sebesar 53,75\%(43 orang) dan persentase yang tidak mengalami nyeri punggung bawah sebesar 15\% (12 orang). Untuk persentase indeks massa tubuh yang tidak berisiko $(\leq 23,0)$ sebesar $31,25 \%$ (25 orang). Persentase responden dengan indeks massa tubuh tidak berisiko yang mengalami nyeri punggung bawah sebesar 21,25\% (17 orang) dan persentase yang tidak mengalami nyeri punggung bawah sebesar $10 \%$ (8 orang). Hal tersebut menunjukkan pemain game online lebih banyak yang memiliki indeks massa tubuh $>23,0$ /berisiko. Setelah data dianalisis dengan uji chi square, didapatkan nilai kemaknaan $\mathrm{p}=0.152$. Nilai ini menunjukkan tidak adanya hubungan antara keluhan nyeri punggung bawah dengan faktor risiko indeks massa tubuh (Tabel 3).

Hasil tabel 4 menunjukan bahwa dari 20 responden yang memiliki sikap kerja ergonomis, keseluruhan responden (25\%) tidak mengalami keluhan nyeri punggung bawah. Sedangkan dari 60 responden yang memiliki sikap kerja yang tidak ergonomis, keseluruhan responden (75\%) mengalami keluhan nyeri punggung bawah. Dari hasil uji chi-square didapatkan nila $\mathrm{p}=0,000$. Nilai ini menunjukkan adanya hubungan yang bermakna antara posisi duduk dengan nyeri punggung bawah.
Berdasarkan lama duduk responden menunjukan bahwa dari 57 responden yang lama duduk $>4$ jam dalam sehari, keseluruhan responden (71,25\%) mengalami keluhan nyeri punggung bawah dan 23 responden (28,75\%) yang lama duduk $\leq 4$ jam dalam sehari tidak mengalami keluhan nyeri punggung bawah. Dari uji chi square didapatkan nilai $\mathrm{p}=0,000$, nilai menunjukkan adanya hubungan yang bermakna antara lama duduk dengan keluhan nyeri punggung bawah (Tabel 5).

\section{PEMBAHASAN}

Subjek penelitian adalah pemain game online di kecamatan Denpasar Barat, dapat dijelaskan bahwa dari 80 responden, berdasarkan distribusi usia berkisar 17 hingga 30 tahun dengan rerata usia 20,86 tahun. Distribusi usia dapat digolongkan menjadi usia $<25$ tahun dan $\geq 25$ tahun. Pembagian usia ini berdasarkan dengan penelitian yang dilakukan oleh Nurzanah (2015) yang membagi kelompok usia tersebut pada penelitian hubungan nyeri punggung bawah pada tenaga kerja bongkar muat di Pelabuhan Belawan Medan. Hasil penelitian menunjukkan didapatkan responden berusia $<25$ tahun dengan persentasenya sebesar $90 \%$ (72 orang). Persentase responden yang berusia $<25$ tahun yang mengalami nyeri punggung bawah sebesar 65\% (52 orang) dan persentase yang tidak mengalami nyeri punggung bawah sebesar $25 \%$ (20 orang). Pada usia $\geq 25$ tahun sebesar $10 \%$ (8 orang). Persentase responden yang berusia $\geq 25$ tahun yang mengalami nyeri punggung bawah sebesar $10 \%$ (8 orang) dan persentase responden yang tidak mengalami nyeri punggung bawah sebesar $0 \%$ (0 orang). ${ }^{7}$ Hal tersebut menunjukkan bahwa pemain game online lebih banyak direntang usia $<25$ tahun.

Berdasarkan indeks massa tubuh dibagi menjadi 2 golongan, yaitu indeks massa tubuh yang berisiko $(>23,0)$ dan indeks massa tubuh tidak berisiko $(<23,0)$. Hal ini merujuk pada data WHO yang menyebutkan bahwa indeks massa tubuh normal yaitu sebesar 23,0. Responden dengan indeks massa tubuh bersiko $(>23,0)$ didapatkan sebesar $68,75 \%$ 
(55 orang). Persentase responden dengan indeks massa tubuh berisiko yang mengalami nyeri punggung bawah sebesar 53,75\% (43 orang) dan persentase yang tidak mengalami nyeri punggung bawah sebesar 15\% (12 orang). Untuk persentase indeks massa tubuh yang tidak berisiko $(\leq 23,0)$ sebesar $31,25 \%$ (25 orang). Persentase responden dengan indeks massa tubuh tidak berisiko yang mengalami nyeri punggung bawah sebesar $21,25 \%$ (17 orang) dan persentase yang tidak mengalami nyeri punggung bawah sebesar $10 \%$ (8 orang). Hal tersebut menunjukkan pemain game online lebih banyak yang memiliki indeks massa tubuh $>23,0$ /berisiko.

Berdasarkan posisi duduk dibagi menjadi posisi duduk yang ergonomi dan tidak ergonomi berdasarkan metode RULA (Rapid Upper Limb Assessment) yang digunakan. Hal ini berdasarkan penelitian sebelumnya yang dilakukan oleh Natosba (2016) yang mengelompokkan menjadi posisi duduk ergonomis dan tidak ergonomis pada penelitian pengaruh sikap duduk ergonomis terhadap kejadian low back pain pada penenun songket di kampong BNI 46. Berdasarkan hasil penelitian, didapatkan responden dengan posisi duduk yang ergonomis persentasenya sebesar 25\% (20 orang) dan posisi duduk yang tidak ergonomis sebesar $75 \%$ (60 orang). ${ }^{8}$ Hal tersebut menunjukkan bahwa sikap kerja yang tidak ergonomis lebih banyak pada para pemain game online dari pada sikap duduk yang ergonomis.

Berdasarkan lama duduk dapat dibagi menjadi lama duduk $\leq 4$ jam dan $>4$ jam. Pembagian ini berdasarkan penelitian yang telah dilakukan sebelumnya oleh Santosa (2016) yang mengelompokkan menjadi lama duduk $\leq 4 \mathrm{jam}$ dan $>4$ jam pada penelitian korelasi lama duduk dengan nyeri punggung bawah pada pekerja Hotel Grand Santhi Denpasar. Berdasarkan hasil penelitian, terdapat responden yang duduk $\leq 4$ jam dengan persentasenya sebesar $28,75 \%$ (23 orang) dan lama duduk yang $>4$ jam sebesar 71,25\% (57 orang). Hal tersebut menunjukkan bahwa pemain game online lebih banyak yang duduk $>4$ jam dari pada yang duduk $\leq 4$ jam. Untuk keluhan nyeri punggung bawah dibagi menjadi nyeri punggung bawah dan tidak nyeri punggung bawah. Dari hasil terlihat keluhan nyeri punggung bawah dengan persentasenya sebesar $75 \%$ (60 orang) dan tidak nyeri punggung bawah sebesar 25\% (20 orang). ${ }^{9}$ Hal tersebut menunjukkan bahwa pemain game online lebih banyak yang mengeluhkan nyeri punggung bawah daripada tidak mengeluhkan nyeri pada punggung bawahnya.

Hasil penelitian menunjukan bahwa dari 20 responden yang memiliki sikap kerja ergonomis, keseluruhan responden (25\%) tidak mengalami keluhan nyeri punggung bawah. Sedangkan dari 60 responden yang memiliki sikap kerja yang tidak ergonomis, keseluruhan responden (75\%) mengalami keluhan nyeri punggung bawah. Dari hasil uji chi-square didapatkan nila $\mathrm{p}<0,05$. Temuan ini menunjukkan adanya hubungan yang bermakna antara posisi duduk dengan keluhan nyeri punggung bawah. Hasil ini sesuai dengan penelitian yang dilakukan Pirade (2013) Posisi duduk yang keliru merupakan penyebab adanya masalah-masalah punggung khususnya nyeri punggung bawah. Posisi duduk dapat menyebabkan peregangan pada tulang punggung sehingga timbulnya keluhan nyeri pada daerah punggung. Tekanan pada bagian tulang belakang akan meningkat pada saat duduk, dibandingkan pada saat berdiri ataupun berbaring. ${ }^{10}$

Sebagian responden memiliki sikap duduk yang tidak ergonomis berdasarkan metode RULA (Rapid Upper Limb Assesment). Metode RULA (Rapid Upper Limb Assesment) pada penelitian ini diobservasi langsung kepada sampel penelitian disaat dilakukan penelitian di lapangan. Kemudian pada saat bermain perlu diperhatikan postur tubuh dalam keadaan seimbang agar dapat bermain dengan nyaman dan tahan lama. Duduklah dengan lutut tetap setinggi atau sedikit lebih tinggi panggul (gunakan penyangga kaki) dan sebaiknya kedua tungkai tidak saling menyilang. Jaga agar kedua kaki tidak menggantung dan hindari duduk dengan posisi yang sama lebih dari 20-30 menit. Selama duduk, istirahatkan siku dan lengan pada kursi, jaga bahu tetap rileks. ${ }^{11}$ Beban statis pada otot merupakan sebab utama nyeri dan lelah oleh karena itu tata ruang sikap kerja harus dibuat sedemikian rupa sehingga beban kerja seminimal mungkin. ${ }^{12}$

Berdasarkan hasil penelitian menunjukan bahwa dari 57 responden yang lama duduk $>4$ jam dalam sehari, keseluruhan responden $(71,25 \%)$ mengalami keluhan nyeri punggung bawah dan 23 responden $(28,75 \%)$ yang lama duduk $\leq 4$ jam dalam sehari tidak mengalami keluhan nyeri punggung bawah . Dari uji chi square didapatkan nilai $\mathrm{p}<0,05$ menunjukkan adanya hubungan yang bermakna antara lama duduk dan insiden nyeri punggung.

Lama duduk mempunyai hubungan dengan keluhan nyeri punggung bawah. Hal ini sesuai dengan kajian pustaka yang menyatakan dalam penelitian yang dilakukan oleh Samara dkk dengan metode case control, menyatakan bahwa duduk selama 1,5 sampai 5 jam mempunyai risiko 2,35 kali lebih besar untuk terjadinya nyeri punggung bawah. Orang yang bekerja dengan posisi duduk selama setengah hari waktu kerja atau lebih memiliki risiko relatif 1,6 kali untuk terjadinya nyeri punggung bawah. ${ }^{13}$ Demikian pula pada penelitian Sumekar dan Natalia menyatakan bahwa lama duduk >4 jam menyebabkan terjadinya nyeri punggung bawah pada hampir seluruh sampel penelitian. ${ }^{14}$ Keadaan tersebut mengakibatkan lebih 
sering terjadi gangguan/kerusakan sehingga terjadi kelelahan dan iskemia jaringan di sekitar daerah tersebut, selanjutnya ditambah jaringan peka nyeri yang banyak di sekitar vertebra lumbalis sehingga mempunyai potensi lebih besar untuk menjadi nyeri oleh karena kondisi hiperalgesia. Sehingga diantara waktu kerja harus disediakan istirahat yang jumlahnya antara 15-30\% dari seluruh waktu kerja. Apabila jam kerja melebihi dari ketentuan tersebut akan ditemukan hal-hal seperti penurunan kecepatan kerja, gangguan kesehatan, angka absensi karena sakit meningkat, yang dapat mengakibatkan rendahnya tingkat produktivitas kerja. ${ }^{15}$

\section{SIMPULAN}

Terdapat hubungan bermakna antara faktor posisi duduk dengan kejadian nyeri punggung bawah. Terdapat hubungan bermakna antara faktor lama duduk dengan kejadian nyeri punggung bawah.

\section{KONFLIK KEPENTINGAN}

Penulis menyatakan tidak terdapat suatu konflik kepentingan terhadap publikasi dari artikel ini.

\section{PENDANAAN}

Penelitian ini tidak mendapatkan suatu pendanaan yang diberikan oleh pemerintah ataupun lembaga swasta lainnya.

\section{KONTRIBUSI PENULIS}

Konsep penelitian: Putu Gede Pradipta Mahardika Wijaya, Ida Ayu Sri Wijayanthi, Ketut Widyastuti. Pengumpulan data, input data dan pengolahan data: Putu Gede Pradipta Mahardika Wijaya. Penyusunan naskah Penelitian: Putu Gede Pradipta Mahardika Wijaya.

\section{ETHICAL CLEARANCE NUMBER}

2627/UN.14.2.2.VII.14/LP/2018.

\section{DAFTAR PUSTAKA}

1. Qomariyah AN. Perilaku Penggunaan Internet pada Kalangan Remaja di Perkotaan. Perilaku Penggunaan Internet pada Kalangan Remaja di Perkotaan. 2013. 53(9), pp.1689-1699
2. Pratiwi PC. et al. Perilaku Adiksi Game-online Ditinjau dari Efikasi Diri Akademik dan Keterampilan Sosial pada Remaja di Surakarta. Jurnal Ilmiah Psikologi Candrajiwa. 2010. 1(2), pp.1 - 15.

3. Fauziah ER. Pengaruh Game Online Terhadap Perubahan Perilaku Anak Smp Negeri 1 Samboja. Imu Komunikasi. 2013. 1(3), pp.1-16. Available at: ejournal.ilkom.fisip-unmul.ac.id.

4. Yanto R., Pengaruh Game Online terhadap perilaku Remaja. Universitas Andalas. 2011. 1(1), pp.1-13.

5. Griadhi, Mediastama I Gd, Silakarma Dedi A., Hubungan Antara Lama Duduk Dengan Sindroma Piriformis Pada Pemain Game Online Di Game Center Go-Kool Denpasar. 2014.,015.

6. Rachmawati LDA., Hubungan Sikap Kerja Duduk Dengan Keluhan Nyeri Punggung Bawah Pada Pekerja Rental Komputer Di Pabelan Kartasura. 2008.

7. Nurzannah, Sinaga M, Salma U. Hubungan Faktor Resiko Dengan Terjadinya Nyeri Punggung Bawah (Low Back Pain) Pada Tenaga Kerja Bongkar Muat (Tkbm) Di Pelabuhan Belawan Medan Tahun 2015. Medan: Universitas Sumatera Utara. 2015.

8. Natosba J, Jaji. Pengaruh Posisi Ergonomis Terhadap Kejadian Low Back Pain Pada Penenun Songket Di Kampung Bni 46. Jurnal Keperawatan Sriwijaya 2016. v3-no.2p4.

9. Santosa A., Widyadharma Eka IP., Purwata ET. Korelasi Lama Duduk Dengan Nyeri Punggung Bawah Pada Pekerja Hotel the Grand Santhi Denpasar.Denpasar: Universitas Udayana. 2016.

10. Pirade A., Angliadi E. \& Sengkey LS. Hubungan Posisi Dan Lama Duduk Dengan Nyeri Punggung Bawah (Npb) Mekanik Kronik Pada Karyawan Bank. Jurnal Biomedik (JBM). 2013. Volume 5, Nomor 1, Suplemen, hlm. S98-104

11. Wardaningsih I. Pengaruh Sikap Kerja Duduk Pada Kursi Kerja Yang Tidak Ergonomis Terhadap Keluhan Otot-Otot Skeletal Bagi Pekerja. 2010.

12. Susetyo J., Titin IS., Sigit TS. Pengaruh Shift Kerja Terhadap Kelelahan dengan Metode Bourdon Wiersma dan 30 Items of Rating Scale. Jurnal Teknologi, Volume 5 No.1.Yogyakarta: Fakultas Teknologi Industri Institut Sains dan Teknologi AKPRIND. 2012.

13. Samara D., et.al. Duduk Statis Sebagai Faktor Risiko Terjadinya Nyeri Punggung Bawah Pada Pekerja Perempuan, Jurnal Universa Medicina. 2005. Vol.24 No.2. Di unggah mei 2014. Dari http://www.univmed.org/ wpcontent/uploads/2011/02/.

14. Sumekar DW., Natalia D. Nyeri Punggung pada Operator Komputer Akibat Posisi dan Lama Duduk. 2008. http:// www.mkbonline.org/web/index.php/ MKB/artic.Diakses tanggal 2 November 2018.

15. Yusuf M. Design of Jewel Stone Sharpener to Increase Jewel Worker Work Productivity in Bali. ICETIA. 2014. ISSN 2407-4330. 352-436.

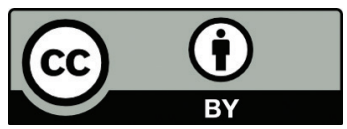

This work is licensed under a Creative Commons Attribution 